\title{
Discussing the role of tropical and subtropical moisture sources in cold season extreme precipitation events in the Mediterranean region from a climate change perspective
}

S. O. Krichak et al.

Correspondence to: S. O. Krichak (shimonk@ post.tau.ac.il)

The copyright of individual parts of the supplement might differ from the CC-BY 3.0 licence. 
Dear Dr. Krichak-

My name is Jinny Nathans and I'm the Permissions Officer at AMS. Your question was referred to me. This signed message constitutes permission to use the material requested in your email below.

You may use the figures in your upcoming publication with the following conditions:

+ please include the complete bibliographic citation of the original source for each, and

+ please include the following statement with that citation for each: OAmerican Meteorological Society. Used with permission.

AMS does not provide image files of figures for which it grants republication permission.

Thanks very much for your request and if you need any further information, please get in touch with me. My contact information is below.

Regards,

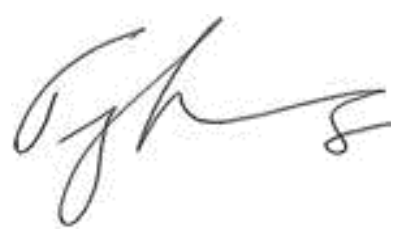

Jinny Nathans

Permissions Officer

American Meteorological Society

inathans@ametsoc.org

617 226-3905

On Thu, Dec 10, 2015 at 11:37 AM, Simon Krichak<shimonk@post.tau.ac.il> wrote:

Dear AMS,

I am now working on a review paper which is currently on a final stage of its final revision before publication in a Special Issue: Climate change, extreme events and hazards in the Mediterranean region of the Natural Hazards and Earth System Sciences which is an interactive open-access journal of the European Geosciences Union. In this 
paper I plan to include figures from two AMS journal articles and am asking for your permission for it. Ideally, it is best to include originals with at least 300 dpi as TIFF, EPS, or JPG files. Would it be possible to obtain the original high resolution figures from the AMS?

I plan to include figures from the following two AMS journal articles.

1) Dacre, H.F., Clark, P.A., Martinez-Alvarado, O., Stringer, M.A., Lavers, D.A.: How do atmospheric rivers form? Bull Amer Meteorol Soc doi: 10.1175/BAMS-D-1400031.1, 2015 (Figure 8).

2) Sodemann, H., and Stohl, A.: Moisture origin and meridional transport in atmospheric rivers and their association with multiple cyclones, Mon. Wea. Rev., 141, 2850-2868, 2013 (Figure 10).

Thank you.

Best wishes.

Simon Krichak

$* * * * * * * * * * * * * * * * * * * * * * * * * * * * * * * * * * * * * * * * * * * * * * * * * * * *$

Simon O. Krichak

Science Advisor to the Israel Meteorological Service

Associate Professor, Emeritus

Department of Geosciences

Tel-Aviv University, Tel-Aviv 69978, ISRAEL

TEL Dept. Secretary: 972-3-6408633; Office: 972-3-6405086; 
FAX: 972-3-6409282 Home: 972-3-9515748

Mobile: +972522239769

e-mail: shimonk@post.tau.ac.il

HomePage: http://www.tau.ac.il/ shimonk/ 